Revue de sciences sociales sur les arts, la culture et les idées

\title{
Le rendez-vous manqué du savant, du populaire et des Distinction Studies
}

The Missed Encounter of Le Savant et le Populaire and the Distinction Studies

El desencuentro entre El Sabio y el Popular y los Distinction Studies

\section{Philippe Coulangeon}

\section{(c) OpenEdition}

Journals

Édition électronique

URL : http://journals.openedition.org/bssg/131

DOI : $10.4000 /$ bssg.131

ISSN : 2490-9424

Éditeur

Presses universitaires de Vincennes

Référence électronique

Philippe Coulangeon, "Le rendez-vous manqué du savant, du populaire et des Distinction Studies », Biens Symboliques / Symbolic Goods [En ligne], 1 | 2017, mis en ligne le 15 octobre 2017, consulté le 04 mars 2021. URL : http://journals.openedition.org/bssg/131 ; DOI : https://doi.org/10.4000/bssg.131 

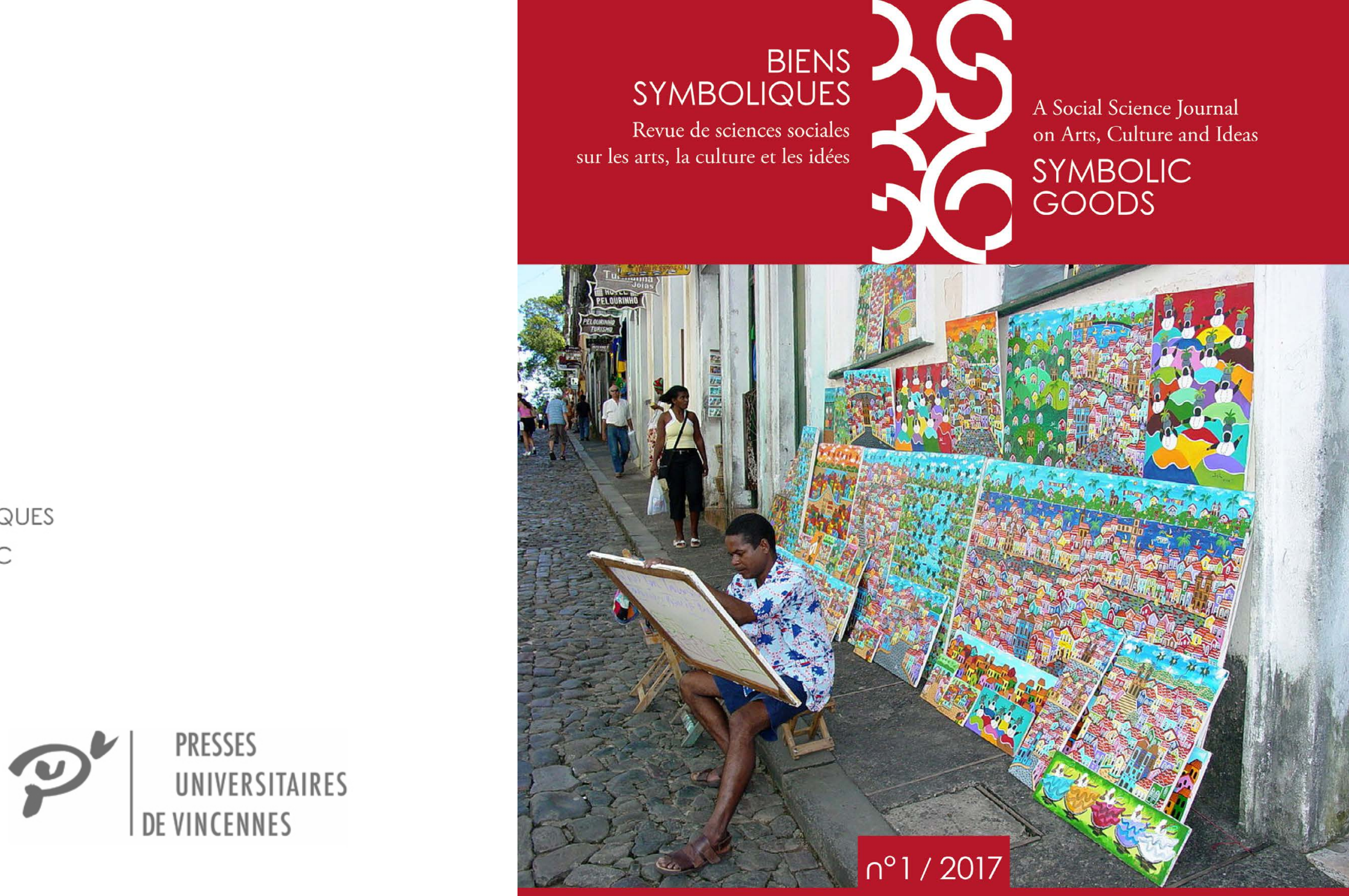

\section{Artistes ordinaires \\ Ordinary Artists}




\title{
Le rendez-vous manqué du savant, du populaire et des Distinction Studies
}

\author{
Philippe Coulangeon
}

Le Savant et le Populaire est à peu de choses près contemporain de l'essor, à l'orée des années 1990, d'un vaste ensemble de recherches, en grande partie initiées outre-Atlantique, fondées sur la mise à l'épreuve empirique des propositions théoriques de Bourdieu, et plus précisément des thèses exposées dans La Distinction. Cette mise à l'épreuve, qui s'est appuyée le plus souvent sur le recours aux outils de l'analyse statistique de données d'enquête, se donnait pour ambition de soumettre la « robustesse » des thèses de Bourdieu à l'épreuve des faits. Nombre des auteurs qui ont contribué à cette entreprise de relecture critique empiriquement équipée des thèses de Bourdieu ont été amenés à mobiliser ou à élaborer eux-mêmes des modèles théoriques alternatifs, ou à tout le moins à en esquisser les contours.

Deux séries de publications jalonnent l'émergence de ces « distinction studies », pour reprendre l'expression de Julien Duval (2010). L'ouvrage de Michèle Lamont, Moral, Money and Manners, en 1992, traduit en français en 1995 sous le titre La morale et l'argent (Lamont 1995 [1992]), d'une part, et la série d'articles publiés à partir de 1992 par Richard Peterson et divers co-auteurs sur le thème de l'omnivorité (Peterson 1992 et 1997 ; Peterson \& Simkus 1992 ; Peterson \& Kern 1996). L'ouvrage de Michèle Lamont, à partir d'une double série d'entretiens menés auprès de cadres supérieurs et de managers dans deux agglomérations françaises (Paris et Clermont-Ferrand) et étasuniennes (Boston et Minneapolis), entendait notamment souligner la forte idiosyncrasie des formes de cooptation et de clôture à l'œuvre au sein des classes supérieures des deux pays, et s'appuient sur des frontières symboliques davantage liées aux critères esthétiques et culturels en France, tandis qu'aux États-Unis, prévalaient plutôt, selon l'auteure, des critères d'ordre moral et économique. La série d'articles de Peterson et de ses co-auteurs soulignait quant à elle l'émergence d'une hiérarchisation sociale des préférences et des habitudes culturelles davantage fondée sur le degré de diversité des répertoires de pratiques et de goûts, plutôt que sur l'opposition des répertoires savants et populaires associée, à tort ou à raison, j'y reviendrai, au Bourdieu de La Distinction. Ce corpus s'est ensuite enrichi, notamment des thèses développées une dizaine d'années plus tard par Bernard Lahire dans le registre voisin de la "dissonance culturelle » (Lahire 2004).

Dans ce contexte, il est notable que la référence à l'ouvrage de Claude Grignon et Jean-Claude Passeron, qui proposait lui aussi, à sa manière, une relecture critique de la sociologie de Bourdieu, a été en revanche assez peu mobilisée. Cette marginalisation tient sans doute pour partie au fait que, jamais traduit en anglais, Le Savant et le Populaire demeure peu 
connu à l'étranger, en particulier dans le monde anglo-saxon, où ces recherches se sont principalement développées depuis une vingtaine d'année. II ne me semble pas pourtant que les obstacles linguistiques à la circulation de l'ouvrage épuisent l'explication de cette quasi-absence, qui doit aussi beaucoup, me semble-t-il, à la forme de l'ouvrage, au fait en particulier qu'il prétend ouvrir le débat entre les propositions théoriques existantes plutôt que leur opposer une alternative. Le livre de Grignon et Passeron porte la marque d'une double filiation. Celle de Pierre Bourdieu, bien sûr, dont les deux auteurs ont été proches, mais aussi celle de Richard Hoggart, dont l'un et l'autre ont contribué à diffuser l'œuvre en France (Hoggart 1970 [1957]), et, plus largement des cultural studies, deux filiations que l'ouvrage met en tension, en en pointant les dérives réciproques. Dérive « misérabiliste », s'agissant de la filiation bourdieusienne, qui porte à envisager les cultures populaires sous l'angle exclusif de leur domination ; dérive « populiste », s'agissant de l'héritage des cultural studies, qui, tout à la célébration de l'autonomie de ces répertoires populaires, oublie les rapports de domination dans lesquels ils s'inscrivent. Cette mise en tension ne constituait pas à proprement parler un corps d'hypothèses ou une théorie alternative aux deux courants théoriques dont elle s'alimentait, mais une invitation au dépassement de leurs apories. II faut du reste garder en tête qu'en France en particulier, cette double filiation structurait aussi, à l'époque, la construction de doctrines de politique culturelle opposées. Celle, pour aller vite, de la démocratisation culturelle, qui se donnait pour objectif l'accès du plus grand nombre aux répertoires consacrés et celle de la démocratie culturelle, qui visait à l'épanouissement et à la reconnaissance de la diversité des répertoires et des esthétiques (Bellavance et al. 2000).

La forme même de l'ouvrage, en mettant parfois clairement en avant leurs désaccords, traduisait l'ambivalence de la position des auteurs sur ces questions, leur « embarras », pour reprendre le terme utilisé dans l'avant-propos du livre. Plus de vingt-cinq ans après sa parution, il semble ainsi que Le Savant et le Populaire désignait un horizon de recherche ouvert qui invitait à une sociologie de la domination symbolique attentive à l'autonomie relative des cultures dominées, laquelle n'était pas nécessairement perçue comme synonyme de résistance mais pouvait aussi correspondre simplement à l'oubli ou la neutralisation transitoire des rapports de pouvoir symboliques entre les classes sociales. II augurait aussi - puisque, comme on vient de le rappeler, le débat ne se cantonnait pas à la sphère académique - d'un dépassement possible des clivages fondateurs de la doctrine française en matière de politique culturelle.

On perçoit ainsi le parti empirique qui aurait pu être tiré de ce programme et l'on s'interroge sur les raisons pour lesquelles celui-ci ne s'est pas pleinement imposé dans le champ des " distinction studies » évoqué plus haut. La première raison qui vient à l'esprit est assez prosaïque. Elle tient au fait que ce programme s'avérait assez rétif aux formes ordinaires d'opérationnalisation de la statistique d'enquête à laquelle s'abreuve une bonne part des recherches menées dans ce champ. II n'est en effet pas aisé d'objectiver les gradations du consentement à la domination ou, au contraire, de la résistance à l'ordre de la légitimité culturelle au travers de questionnaires qui renseignent pour l'essentiel des indicateurs 
relatifs à l'orientation des préférences et à la fréquence des pratiques. De nouveau, le fait que l'ouvrage emprunte la forme du débat décourage sa mobilisation comme sa mise à l'épreuve. Le livre ne défend pas de thèse univoque et n'offre pas de prise évidente au test d'hypothèse.

La deuxième raison pour laquelle Le Savant et le Populaire n'est pas parvenu à faire école dans le champ de la sociologie culturelle des rapports de classes dans lequel il semblait devoir s'inscrire, tient sans doute aussi aux critiques assez vives dont l'ouvrage a fait l'objet, en particulier chez Bourdieu et les chercheurs qui se réclamaient de son influence. Ces critiques culminent dans le chapitre 2 des Méditations pascaliennes de Bourdieu (« Les trois formes de l'illusion scolastique », Bourdieu 2003 [1997] : 71-132). La charge de Bourdieu contre « l'esthétisme populiste » des entreprises de réhabilitation des cultures populaires (Bourdieu 2003 [1997] : 109-111), semble en effet très directement dirigée contre Le Savant et le Populaire, même si ni l'ouvrage ni ses auteurs n'y sont cités :

Le culte de la « culture populaire » n'est, bien souvent, qu'une inversion verbale et sans effet, donc faussement révolutionnaire, du racisme de classe qui réduit les pratiques populaires à la barbarie ou à la vulgarité : comme certaines célébrations de la féminité ne font que renforcer la domination masculine, cette manière en définitive très confortable de respecter le « peuple », qui, sous l'apparence de l'exalter, contribue à l'enfermer ou à l'enfoncer dans ce qu'il est en convertissant la privation en choix ou en accomplissement électif, procure tous les profits d'une ostentation de générosité subversive et paradoxale, tout en laissant les choses en l'état, les uns avec leur culture (ou leur langue) réellement cultivée et capable d'absorber sa propre subversion distinguée, les autres avec leur culture ou leur langue dépourvues de toute valeur sociale ou sujettes à de brutales dévaluations que l'on réhabilite fictivement par un simple faux en écriture théorique. (Bourdieu, 2003 [1997] : 110-111.)

II me semble que l'effet propre de la rupture, personnelle et intellectuelle, de Grignon et Passeron avec Bourdieu dans la marginalisation relative de la référence aux premiers, au sein d'un segment de la recherche en sciences sociales où la référence à Bourdieu est restée dominante, ne doit évidemment pas être occultée ${ }^{1}$

Au total, le fait que Le Savant et le Populaire soit resté assez largement extérieur au corpus théorique mobilisé par les « distinction studies » a sans doute privé ce courant de recherche de l'attention à l'ensemble des opérations et des médiations qui rendent possible l'exercice de la domination symbolique, y compris contre l'expression de résistances, et qui signent l'originalité de la contribution de Grignon et Passeron. Et cette attention semble d'autant plus nécessaire que, du fait notamment du développement de l'industrie de la culture et des médias, la multiplication des acteurs de la prescription culturelle affecte inévitablement les conditions d'exercice monopoliste de cette domination. De ce point de vue, l'ouvrage de Grignon et Passeron suggère que le changement des formes dans lesquelles s'exprime aujourd'hui la dimension culturelle des rapports de classe est aussi, pour partie, un changement de fond. Le régime

1 On se fera une idée de la rudesse de cette rupture à travers le récit et l'analyse qu'en donne Claude Grignon lui-même (Grignon 1996). 
« pluraliste » et « ouvert » qui s'établit par exemple dans la montée de l'éclectisme des goûts et des pratiques ainsi que dans le brouillage des frontières entre les répertoires, a aussi pour corollaire que la domination, pour perdurer, requiert un travail continu d'adaptation à des normes changeantes dans leur contenu - travail qui n'est pas nécessaire lorsque prévaut l'opposition binaire et fermement relayée par l'institution scolaire, en particulier, du savant et du populaire.

Philippe Coulangeon Institut d'études politiques de Paris/ CNRS OSC (Observatoire Sociologique du Changement) http://www.sciencespo.fr/osc/fr/node/1219

\section{Références bibliographiques}

Aron Raymond (1983). Mémoires. Paris, Julliard.

BAKHTINE Mikhaïl (1970). L'CEuvre de François Rabelais et la culture populaire au Moyen Âge et sous la Renaissance. Paris, Gallimard.

BECKER Howard (1988). Les Mondes de l'art. Traduit de l'anglais par Jeanne Bouniort. Paris, Flammarion.

Bellavance Guy, Boivin Micheline, Santerre Lise (dir.) (2000).

Démocratisation de la culture ou démocratie culturelle? Deux logiques d'action publique. Québec, Éditions de l'IQRC.

Bols Géraldine (2008). "Le consentement à la domination littéraire. Degrés et diversité de ses formes chez les écrivains "les moins reconnus" de l'univers littéraire ». Tracés, $14: 55-76$.

Bourdieu Pierre (1979). La Distinction. Critique sociale du jugement. Paris, Minuit.

BOURDIEU Pierre (1984). Questions de sociologie. Paris, Minuit.

BouRdieu Pierre (1988). «Entretien recueilli par Beate Krais ». In BouRdieU Pierre, Chamboredon Jean-Claude, Passeron Jean-Claude, Le Métier de sociologue. Préalables épistémologiques. Paris, Éditions de l'EHESS (cinquième édition).
Bourdieu Pierre (1989). La Noblesse d'État. Paris, Minuit.

BOURDIEU Pierre (1993). "Les contradictions de l'héritage ». In Bourdieu Pierre (dir.), La Misère du monde. Paris, Seuil : 711-718.

Bourdieu Pierre (1998) [1992]. Les Règles de l'art. Genèse et structure du champ littéraire. Paris, Seuil.

BOURDIEU Pierre (1998). La Domination masculine. Paris, Seuil.

Bourdieu Pierre (2003) [1997]. Méditations pascaliennes. Paris, Seuil.

Bourdieu Pierre, Chamboredon Jean-Claude, Passeron Jean-Claude (1968). Le Métier de sociologue. Paris, Mouton.

Bourdieu Pierre \& PASSERon Jean-Claude (1964). Les Héritiers. Les étudiants et la culture. Paris, Minuit.

BouRdieu Pierre \& PASSERON Jean-Claude (1970). La Reproduction Éléments pour une théorie du système d'enseignement. Paris, Minuit.

BOURDIEU Pierre \& WACQUANT Loïc (2014). Invitation à la sociologie réflexive. Paris, Seuil.

BOUTIER Jean (2008). "Quelques réflexions rétrospectives sur les histoires de la "culture populaire" ». Journée d'étude "Le Savant et le Populaire, 1989-2008. Retour sur un débat en suspens ». SHADYC, EHESS Marseille (non publié).

BouverESSE Jacques (2008). " Le besoin de croyance et le besoin de vérité ». Agone, 38-39: 281-306.

BuRKE Peter (1978). Popular Culture in Early Modern Europe. Londres, Temple Smith.

BUSCATTO Marie (2014). Sociologies du genre. Paris, Armand Colin.

Busino Giovanni (2006). «Entretien avec Dominique Schnapper ». Revue européenne des sciences sociales, XLIV(135). [En ligne] http://ress. revues.org/271 [consulté le 12 octobre 2016]

Casanova Pascale (2008) [1999]. La République mondiale des lettres. Paris, Seuil.

ChAPOULIE Jean-Michel (1991). " La seconde fondation de la sociologie française, les États-Unis et la classe ouvrière ». Revue française de sociologie 32(3) : 321-364.

CHARTIER Roger (2001). "Culture écrite et littérature à l'âge moderne 》. Annales. Histoire, Sciences sociales, 56(4) : 783-802.

COHEN Déborah (2010). La Nature du peuple. Les formes de l'imaginaire social (XVIII/ $/ X I^{e}$ siècles). Seyssel, Champ Vallon. 
ColleCtIF (1988). « Histoire et sciences sociales. Un tournant critique? ». Annales ESC, 2 : 291-293.

Collectif Révoltes logiques (1984). L'Empire du sociologue. Paris, La Découverte.

Collovald Annie (1988). "Identité(s) stratégiques(s) », Actes de la recherche en sciences sociales, $73: 29-40$.

Connell Raewyn (1995). Masculinities. Cambridge, Polity Press.

CoRnu Tanguy (2008). « L'ambiguïté du concept de domination symbolique dans Le Savant et le Populaire ". Journée d'étude "Le Savant et le Populaire, 1989-2008. Retour sur un débat en suspens ». SHADYC, EHESS Marseille (non publié).

CoULANGEON Philippe \& DuvAL Julien (2013). Trente ans après La Distinction de Pierre Bourdieu. Paris, La Découverte.

COULANGEON, Philippe \& DUVAL Julien (2013). «Introduction ». In EID. (dir.), Trente ans après La Distinction de Pierre Bourdieu. Paris, La Découverte. Daudet Alphonse (1868). Le Petit Chose. Paris, Pierre-Jules Hetzel.

DeBEAUvaIs Michel (1976). L'Université ouverte : les dossiers de Vincennes. Grenoble, Presses Universitaires de Grenoble.

Dragomir Lucia (2011). «L'Union des écrivains. Un modèle institutionnel et ses limites ». Vingtième siècle, $109: 59-70$.

Ducournau Claire (2017). "Les deux (ou trois) carrières de Richard Hoggart. De la fondation des cultural studies aux appropriations de la sociologie française ". Revue d'anthropologie des connaissances, 11(3) : 263-282.

DUMONT Fabienne \& SoFIO Séverine (2007). " Esquisse d'une épistémologie de la théorisation féministe en art ». Cahiers du genre, 43 : 17-43.

DuVAL Julien (2010). "Distinction studies ". Actes de la recherche en sciences sociales, 181-182 : 146-156.

ELIAS Norbert (1991). La Société des individus. Traduit de l'allemand par Jeanna Etoré. Paris, Fayard.

FABIANI Jean-Louis (dir.) (2001). Le Goût de l'enquête. Pour Jean-Claude Passeron. Paris, L'Harmattan.

FossÉ-PoliAK Claude (2006). Aux frontières du champ littéraire. Sociologie des écrivains amateurs. Paris, Économica.
Foucault Michel (1973). Moi, Pierre Rivière ayant égorgé ma mère, ma sœur et mon frère... Paris, Gallimard/Julliard.

FouCAULt Michel (1994). Dits et écrits, t. 1 et 2. Paris, Gallimard.

GaBORIAU Philippe (1995). Le Tour de France et le vélo. Histoire sociale d'une épopée contemporaine. Paris, L'Harmattan.

GaBORIAU Philippe (2003). Les Spectacles sportifs. Grandeurs et décadences. Paris, L'Harmattan.

GinzBURG Carlo (1980) [1976]. Le Fromage et les vers. L'univers d'un meunier du XVI siècle [Il formaggio e i vermi. Il cosmo di un mugnaio del Cinquecento, Turin, Einaudi]. Traduit de l'italien par Monique Aymard. Paris, Flammarion.

Grenier Jean-Yves, Grignon Claude, Menger Pierre-Michel (dir.) (2001). Le Modèle et le récit. Paris, Maison des Sciences de l'Homme.

GriGnon Claude (1996). " Le savant et le lettré, ou l'examen d'une désillusion ", Revue européenne des sciences sociales, 103 : 81-98.

GriGnON Claude (2001). "La formalisation et les sciences du récit, le cas de la sociologie ». In Grenier Jean-Yves, Grignon Claude, Menger Pierre-Michel (dir.), Le Modèle et le récit. Paris, Maison des Sciences de l'Homme : 7-43.

GriGnon Claude \& Kordon Claude (dir.) (2009). Sciences de l'homme et sciences de la nature, essais d'épistémologie comparée. Paris, Maison des Sciences de l'Homme.

GRIGNON Claude \& PASSERON Jean-Claude (1982). Sociologie de la culture et sociologie des cultures populaires. Paris, Documents du GIDES, 4.

Grignon Claude \& PAsseron Jean-Claude (1985). Enquête. Cahiers du CERCOM, 1 (« À propos des cultures populaires »). [En ligne] https:// enquete.reveues.org/2 [consulté le 26 juin 2017].

Grignon Claude \& PASSERON Jean-Claude (2015) [1989]. Le Savant et le Populaire. Misérabilisme et populisme en sociologie et en littérature.

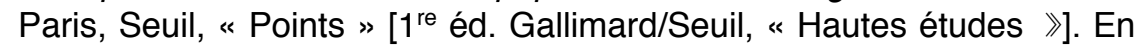
espagnol : Grignon Claude \& PASSERON Jean-Claude (1991). Lo culto y lo popular : miserabilismo y populismo en sociologia y en literatura. Traduction de María Sonderéguer. Buenos Aires, Ediciones Nueva Vision; GRIGNON Claude \& PASSERON Jean-Claude (1992). Lo culto y lo popular miserabilismo y populismo en sociologia y en literatura. Traduction de 
Fernando Alvarez-Uria et Julia Varela. Madrid, Las Ediciones de La Piqueta.

Grignon Claude, Collovald Annie, Pudal Bernard, Sawicki Frédéric (1991). " Un savant et le populaire. Entretien avec Claude Grignon ». Politix, 13 : 35-42.

GRUEL Louis (2004). La Rébellion de 68. Une relecture sociologique. Rennes, Presses Universitaires de Rennes.

GUILLAUMIN Colette (2002) [1972]. L'Idéologie raciste. Paris, Gallimard.

Hall Stuart \& JefFERSON Tony (dir.) (1976). Resistance through Rituals : Youth Subcultures in Post-War Britain. Londres, Hutchinson.

Hammou Karim (2008). «Penser le pouvoir avec Le Savant et le Populaire». Journée d'étude "Le Savant et le Populaire, 1989-2008. Retour sur un débat en suspens ". SHADYC, EHESS Marseille (non publié).

HEINICH Nathalie (2000) [1991]. Etre écrivain. Paris, La Découverte.

Hoggart Richard (1970a). La Culture du pauvre. Étude sur le style de vie des classes populaires en Angleterre. Traduit de l'anglais par Françoise Garcia, Jean-Claude Garcia et Jean-Claude Passeron, présentation et index de Jean-Claude Passeron (titre original The Uses of Literacy : Aspects of Working Class Life). Paris, Minuit.

HogGaRT Richard (1970b). Speaking to Each Other, vol. 1. Londres, Chatto et Windus.

HogGaRT Richard (2013) [1991]. 33 Newport Street. Autobiographie d'un intellectuel issu des classes populaires anglaises. Traduit de l'anglais par Christiane Grignon \& Claude Grignon avec la collaboration de Christopher Todd, présentation de Claude Grignon. Paris, Seuil, « Points »

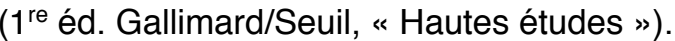

KALIFA Dominique (2005). "Les historiens français et le "populaire" ». Hermès, $42: 54-59$.

KRÉFA Abir (2013). « La quête de l'autonomie littéraire en contexte autoritaire : le cas des écrivains tunisiens ». Sociologie, $4: 395-411$.

KRÉFA Abir (2013). Activités littéraires et rapports sociaux de sexe : le cas des écrivains tunisiens (thèse de doctorat en sociologie). Lyon, Université Lyon 2.

KRÉFA Abir (2014). «Entre injonctions à dire et à taire le corps : les voies étroites de la reconnaissance littéraire pour les écrivaines tunisiennes ». Ethnologie française, 44(4) : 631-642.
LAGRAVE Rose-Marie (1980). Le Village romanesque. Le Paradou, Actes Sud, « Espace-temps ».

LAGRAVE Rose-Marie (1988). "Mensonge romanesque et vérité des romanciers. Une relecture du Village Romanesque ». Études Rurales, $109: 55-73$.

LAGRAVE Rose-Marie (2009). "Filiations intellectuelles et espérance sociale. Figure et œuvre de Placide Rambaud ». Études rurales, 183 51-66.

LAGRAVE Rose-Marie (2010). "Se ressaisir ». Genre, Sexualité \& Société, $4: 1-17$. [En ligne] http://gss.revues.org

LAHIRE Bernard (2004). La Culture des individus : dissonances culturelles et distinction de soi. Paris, La Découverte.

LAHIRE Bernard (2008). La Raison scolaire. École et pratiques d'écriture, entre savoir et pouvoir. Rennes, Presses Universitaires de Rennes.

LahIRE Bernard (2012). Monde pluriel. Penser l'unité des sciences sociales. Paris, La Découverte.

LAMONT Michèle (1995). La Morale et l'argent : les valeurs des cadres en France et aux États-Unis. Paris, Métailié.

LAMONT Michèle (2013). " En quoi Bourdieu a-t-il été utile à notre réflexion ? Le cas des États-Unis ». In CoulANGEON Philippe \& DUVAL Julien (dir.), Trente ans après La Distinction de Pierre Bourdieu. Paris, La Découverte : 59-68.

LevI Giovanni (1989). Le Pouvoir au village. Histoire d'un exorciste dans le Piémont du XVII siècle. Paris, Gallimard.

LINHART Robert (1981). L'Établi. Paris, Minuit.

MACKENZIE Caroline (2012). "Agency, un mot, un engagement ». Rives méditerranéennes, 41(1). [En ligne] http://rives.revues.org/4139 [consulté le 11 mars 2017].

MatHIEU Nicole-Claude (1991). L'Anatomie politique. Paris, Côté-Femmes. MAUGER Gérard (1991). "Enquêter en milieu populaire 》. Genèses, 6 : 125-143.

MAUGER Gérard (2005). « Un apprentissage tardif du métier de sociologue ». In MAUGER Gérard (dir.), Rencontres avec Pierre Bourdieu. Bellecombe-en-Bauges, Le Croquant : 239-257.

MAUger Gérard (2006a). "Sur la violence symbolique ». In MülleR HansPeter \& Sintomer Yves (dir.). Pierre Bourdieu, théorie et pratique. Paris, La Découverte : 84-100. 
MAUGER Gérard (2006b). Les Bandes, le milieu et la bohème populaire. Études de sociologie de la déviance des jeunes des classes populaires (1975-2005). Paris, Belin.

MAUGER Gérard (2013). " Bourdieu et les classes populaires. L'ambivalence des cultures dominées ». In Coulangeon Philippe \& DUVAL Julien (dir.), Trente ans après La Distinction de Pierre Bourdieu. Paris, La Découverte : 243-254.

MAUGER Gérard (2014). « Domination ». Le Lexique socius. [En ligne] http:// ressources-socius.info/index.php/lexique/21-lexique/154-domination [consulté le 14 janvier 2017].

MAUGER Gérard \& FossÉ Claude (1977). La Vie buissonnière. Marginalité petite-bourgeoise et marginalité populaire. Paris, Maspero.

MAUGER Gérard \& Fossé-PoliaK Claude (1985). "Choix politiques et choix de recherches. Essai d'auto-socio-analyse (1973-1984) ». Cahiers " Jeunesses et Sociétés », 3-4-5: 27-121.

MengeR Pierre-Michel (2009). Le Travail créateur. S'accomplir dans l'incertain. Paris, Gallimard/Seuil, « Hautes études ».

Morrison Toni (1990). Playing in the Dark: Whiteness and The Literary Imagination. New York, Vintage Books.

MouLIN Raymonde (1971). "La Culture du pauvre. À propos du livre de Richard Hoggart ». Revue française de sociologie, 12(2) : 255-258.

Moulin Raymonde (1992). L'Artiste, l'institution et le marché. Paris, Flammarion.

MouLIN Raymonde (dir.) (1986). Sociologie del'art. Paris, La Documentation française.

Moulin Raymonde, Passeron Jean-Claude, PAsquier Dominique, PortoVASQUEZ Fernando (1985). Les Artistes, essai de morphologie sociale. Paris, La Documentation Française.

NAUDIER Delphine \& Rollet Brigitte (2007). Genre et légitimité culturelle. Quelle reconnaissance pour les femmes ?. Paris, L'Harmattan.

NAVEL Georges (1945). Travaux. Paris, Gallimard.

Neveu Érik (1999). «Pour en finir avec l'enfantisme. Retours sur enquêtes ". Réseaux, 92-93: 175-201.

Neveu Érik (2008). «Les voyages des cultural studies ». L'Homme, 187$188: 315-341$
NoIRIEL Gérard (1988). Le Creuset français. Histoire de l'immigration (XIXe-XXe siècle). Paris, Seuil.

Olivier DE SARDAN Jean-Pierre (2008). La Rigueur du qualitatif. Les contraintes empiriques de l'interprétation socio-anthropologique. Louvain, Bruylant Academia.

PARETo Vilfredo (1917). Traité de sociologie générale. Traduit de l'italien par Pierre Boven. Lausanne, Payot.

PASQUALI Paul \& SchwaRTZ Olivier (2016). "La Culture du pauvre : un classique revisité. Hoggart, Les classes populaires et la mobilité sociale ». Politix, 114 : 21-45.

Pasqual Paul (2014). Passer les frontières sociales. Comment les " filières d'élite » entrouvrent leurs portes. Paris, Fayard.

PASQUIER Dominique (1989). La Culture des sentiments. L'expérience télévisuelle des adolescents. Paris, Editions de la MSH.

PASQUIER Dominique (2005). " La "culture populaire" à l'épreuve des débats sociologiques ». Hermès, $42: 60-69$.

PASSERON Jean-Claude (2006) [1991]. Le Raisonnement sociologique. Un espace non poppérien de l'argumentation. Paris, Albin Michel, nouvelle édition revue et augmentée (première édition Paris, Nathan).

Passeron Jean-Claude \& Pedler Emmanuel (1991). Le Temps donné aux tableaux. Compte rendu d'une enquête au musée Granet. Marseille, Imerec.

PASSERON Jean-Claude \& GRUMBACH Michel (dir.) (1985). L'CEil à la page : enquête sur les images et les bibliothèques. Paris, Bibliothèque publique d'information, Service des études et de la recherche.

PAsseron Jean-Claude (dir.) (1999). Richard Hoggart en France. Paris, Bibliothèque publique d'information.

PedLeR Emmanuel (2010). « Les sociologies de la musique de Max Weber et Georg Simmel. Une théorie relationnelle des pratiques musiciennes ». L'Année sociologique, 60(2) : 305-330.

Pedler Emmanuel (2016). L'Esprit des lieux. Paris, Éditions de l'EHESS Pedler Emmanuel \& Bourbonnaud David (2002a). « L'offre du festival "in" d'Avignon : effet d'imposition ou stimulation culturelle ? ». Actes du colloque d'Amiens.

Pedler Emmanuel \& Bourbonnaud David (2002b). « La programmation du Festival. Un pacte de confiance entre l'organisation festivalière et son 
public ». In ETHIS Emmanuel (dir.), Avignon : le public réinventé. Paris, La Documentation française : 131-159.

Pedler Emmanuel \& ZerbiB Olivier (2001). Les Nouvelles Technologies à l'épreuve des bibliothèques. Paris, Bibliothèque publique d'information. Peterson Richard A. \& Simkus Albert (1992). " How Musical Tastes Mark Occupational Status Groups ». In LAMONT Michèle \& FouRNIER Marcel, Cultivating differences : Symbolic Boundaries and the Making of Inequality. Chicago, The University of Chicago Press : 152-168.

Peterson Richard A. (1992). « Understanding audience segmentation : From elite and mass to omnivore and univore ». Poetics, 21(4) : 243-258. Peterson Richard A. (1997). «The Rise and Fall of Highbrow Snobbery as a Status Marker ». Poetics, 25(2-3) : 75-92.

Peterson Richard A. \& KeRn Roger M. (1996). « Changing Highbrow Taste : from Snob to Omnivore ». American Sociological Review, 61(5) : 900-907.

PUDAL Bernard (1991). « Le populaire à l'encan ». Politix, $13: 53-64$.

RANCIÈRE Jacques (1981). La Nuit des prolétaires. Archives du rêve ouvrier. Paris, Fayard.

RANCIĖRE Jacques (2011). La Leçon d'Althusser. Paris, La Fabrique.

ReVEL Jacques (dir.) (1996). Jeux d'échelles. La micro-analyse à l'expérience. Paris, Gallimard/Seuil.

Robinson Eric E. (1968). The New Polytechnics. The People's Universities. Harmondsworth, Penguin

RoEDIGER David (1991). The Wages of Whiteness : Race and the Making of the American Working Class. New York, Verso.

SAPIRO Gisèle (2013a). « La carrière internationale de La Distinction ». In CoUlANGEON Philippe \& Duval Julien (dir.), Trente ans après La Distinction de Pierre Bourdieu. Paris, La Découverte : 45-58

SAPIRO Gisèle (2013b). « Le champ est-il national ? La théorie de la différenciation sociale au prisme de l'histoire globale ». Actes de la recherche en sciences sociales, $200: 70-85$

SCHILLING Heinz (1981). Konfessionskonflikt und Staatsbildung. Eine Fallstudie über das Verhältnis von religiösem und sozialem Wandel in der Früh Neuzeit am Beispiel der Grafschaft Lippe. Gütersloh, Bertelsmann.
ScotT James (2008). La Domination et les arts de la résistance. Fragments du discours subalterne. Traduction française par Olivier Ruchet. Paris Éditions Amsterdam.

Servien Pius (1935). Principes d'esthétique. Problèmes d'art et langage des sciences. Paris, Boivin.

SINGLY François (DE) (1998). «Bourdieu : nom propre d'une entreprise collective ». Le Magazine littéraire, 369 : 39-44.

SutTON-SMith Brian (1970). "Psychology of Childlore : The Triviality Barrier ». Western Folklore, 29(1) : 1-8.

TAINE Hyppolite (1858). Essais de critique et d'histoire. Paris, Hachette. Veyne Paul (1971). Comment on écrit l'histoire. Essai d'épistémologie. Paris, Seuil.

Veyne Paul (2008). Foucault. Sa pensée, sa personne. Paris, Albin Michel. WeBER Max (1998) [1921]. Sociologie de la musique. Les fondements rationnels et sociaux de la musique [Die rationalen und soziologischen Grundlagen der Musik, Tübingen, Drei Masken Verlag]. Traduit de l'allemand par Jean Molino et Emmanuel Pedler. Paris, Métailié.

WIMMER Andreas \& GLICK SCHILLER Nina (2002). « Methodological Nationalism and Beyond : Nation-State Building, Migration and the Socia Sciences ». Global Network, 2 : 301-334. 